\title{
A study on the cooling of electronic component by a flat heat pipe
}

\author{
Hamdy HASSAN ${ }^{1}$, Souad HARMAND ${ }^{2}$ \\ ${ }^{1}$ Mechanical engineering Department, Faculty of Engineering, Assuit University, Egypt \\ ${ }^{2}$ UVHC, TEMPO-DF2T, F-59313 Valenciennes, France \\ Phone/Fax number:: +33327511974, +33327511961 \\ e-mail: souad.harmand@univ-valenciennes.fr
}

\begin{abstract}
A three dimensional numerical model for the cooling of an electronic component by using a flat heat pipe (vapor chamber) is presented. The heat pipe consists of two copper flat walls, two copper water wicks and a vapor region sandwiched between the heat pipe wicks. In this paper, a three dimensional hydrodynamic model of the wicks and vapor regions coupled with a three dimensional thermal model of the heat pipe is presented. The hydrodynamic model of the wick and vapor region is obtained by solving numerically the mass, momentum and liquid vapor interface conditions in a three dimensional form. The temperature of the model is obtained by coupling the energy equation in a three dimensional form with the hydrodynamic model. The model are solved numerically by using finite difference method. The results illustrate well the function of the heat pipe and the circulation of the working fluid inside the wick regions. They also shows that ,for power input $107 \mathrm{~W}$, the maximum liquid velocity is about $4.35 \times 10^{-4} \mathrm{~m} / \mathrm{s}$
\end{abstract}

\section{Key words}

Flat heat pipe, Electronic component, Cooling, Hydrodynamic model, Thermal model

\section{Nomenclatures}

$\begin{array}{lll}\text { acc } & \text { accommodation coefficient } & \\ \mathrm{CE} & \text { Ergun's coefficient } & \\ \mathrm{CP} & \text { specific heat } & \mathrm{J} \cdot \mathrm{kg}^{-1} \cdot \mathrm{K}^{-1} \\ \mathrm{~h} & \text { heat transfer coefficient } & \mathrm{W} \cdot \mathrm{m}-2 . \mathrm{K} \\ \mathrm{hfg} & \text { latent heat } & \mathrm{J} \cdot \mathrm{kg}^{-1} \\ \mathrm{~K} & \text { permeability } & \mathrm{m}^{2} \\ \mathrm{~L} & \text { model length } & \mathrm{m} \\ \text { • } & & \\ \mathrm{m} & \text { mass flow rate per unit area } & \mathrm{kg} \cdot \mathrm{m}^{-2} \mathrm{~s}^{-1} \\ \mathrm{M} & \text { molecular Weight } & \mathrm{kg} \cdot \mathrm{mol}^{-1} \\ \mathrm{Max} & \text { Maximum } & \\ \mathrm{n} & \text { normal direction } & \\ \mathrm{p} & \text { pressure } & \mathrm{Pa} \\ q^{\prime \prime} & \text { heat flux } & \mathrm{W} \cdot \mathrm{m}^{-2} \\ \mathrm{r}_{\text {eff }} & \text { effective pore radius } & \mathrm{m} \\ \mathrm{T} & \text { temperature } & \mathrm{K} \\ \mathrm{u} & \text { velocity component at x direction } & \mathrm{m} \cdot \mathrm{s}^{-1}\end{array}$

$\begin{array}{lll}\mathrm{v} & \text { velocity component at y direction } & \mathrm{m} . \mathrm{s}^{-1} \\ \mathrm{~V} & \text { total velocity } & \mathrm{m} \cdot \mathrm{s}^{-1} \\ \mathrm{~W} & \text { velocity component at z direction } & \mathrm{m} \cdot \mathrm{s}^{-1} \\ \mathrm{~W} & \text { model width } & \mathrm{m} \\ \text { Greek } & \text { Symbols } & \\ \mu & \text { dynamic viscosity } & \mathrm{Pa} . \mathrm{s} \\ \varepsilon & \text { porosity } & \\ \rho & \text { density } & \mathrm{kg} \cdot \mathrm{m}^{-3} \\ \lambda & \text { thermal conductivity } & \mathrm{W} \cdot \mathrm{m}^{-1} \cdot \mathrm{K}^{-1} \\ \sigma & \text { Stefan Boltzmann constant } & \mathrm{W} \cdot \mathrm{m}^{-2} \cdot \mathrm{K}^{-4} \\ & \\ \text { Subscripts } & \\ \mathrm{b} & \text { base plate } & \\ \mathrm{C} & \text { capillary } & \\ \mathrm{H} & \text { heater } & \\ \text { in } & \text { interface } & \\ \mathrm{l} & \text { liquid } & \\ \text { max } & \text { maximum } & \\ \text { w } & \text { wick } & \\ \text { sat } & \text { saturation } & \\ \mathrm{v} & \text { vapor } & \\ \infty & \text { cooling fluid } & \\ & & \end{array}$

\section{Introduction}

A flat plate heat pipe founds many applications such as cooling of high power semiconductor chips, electronic equipment and applications in spacecraft radiator segments due to its high thermal conductivity, reliability and low weight penalty [1]. A heat pipe is an evaporation-condensation device for transferring heat in which the latent heat of vaporization is exploited to transport heat over a distance with a corresponding small temperature difference. The heat transport is realized by means of evaporating a liquid in the heat inlet region (called the evaporator) and subsequently condensing the vapor in a heat rejection region (called the condenser). Closed circulation of the working fluid is maintained by capillary action and/or bulk forces. There are two types of flat heat pipe construction; one is transferring heat 
from the evaporator to the condenser over the longitudinal of the vapor region by passing through the adiabatic region. The other type of the flat heat pipe which called vapor chamber transfers the heat through the width of the vapor region. In this construction, the vapor region is placed between two wicks regions. The second type of heat pipe has recently aroused the interest of research [2-6] because it has mainly three dimensional heat transfer through the different regions of the heat pipe which is difficult to modeled with two dimensional model. Another problem of modeling of that construction of heat pipe, is the coupling between the liquid in the two wick regions [2]. In this paper, a three dimensional model is presented for the cooling of an electronic component by a flat heat pipe (vapour chamber) as shown in figure 1. In this work, a three dimensional hydrodynamic model for the wicks and vapor regions coupled with a three dimensional thermal model of the heat pipe is presented. Also, during the 3D hydrodynamic model, the two regions of the wick are coupled together to have the circulation of the fluid through the wick regions which they were not taken into consideration in the earlier works. Also the effect of the returning liquid on the energy equation is taken into consideration.

\section{Mathematical model}

The steady state model is based on the numerical solution of the governing equations of the mass, momentum and energy equation in the two phases, the liquid/vapor interface and the conduction equation in the solid walls as follows:

Solid walls (copper heat pipe walls, heater block, base plate and thermal layers)

$$
\frac{\partial^{2} T}{\partial x^{2}}+\frac{\partial^{2} T}{\partial y^{2}}+\frac{\partial^{2} T}{\partial z^{2}}=0
$$

\section{Vapor region:}

Mass:

$$
\frac{\partial u}{\partial x}+\frac{\partial v}{\partial y}+\frac{\partial w}{\partial z}=0
$$

Momentum:

$$
\begin{aligned}
& \rho_{v}\left[u \frac{\partial u}{\partial x}+v \frac{\partial u}{\partial y}+w \frac{\partial u}{\partial z}\right]=-\frac{\partial p}{\partial x}+\mu_{v}\left[\frac{\partial^{2} u}{\partial x^{2}}+\frac{\partial^{2} u}{\partial y^{2}}+\frac{\partial^{2} u}{\partial z^{2}}\right] \text { (3) } \\
& \rho_{v}\left[u \frac{\partial v}{\partial x}+v \frac{\partial v}{\partial y}+w \frac{\partial v}{\partial z}\right]=-\frac{\partial p}{\partial y}+\mu_{v}\left[\frac{\partial^{2} v}{\partial x^{2}}+\frac{\partial^{2} v}{\partial y^{2}}+\frac{\partial^{2} v}{\partial z^{2}}\right] \text { (4) } \\
& \rho_{v}\left[u \frac{\partial w}{\partial x}+v \frac{\partial w}{\partial y}+w \frac{\partial w}{\partial z}\right]=-\frac{\partial p}{\partial z}+\mu_{v}\left[\frac{\partial^{2} w}{\partial x^{2}}+\frac{\partial^{2} w}{\partial y^{2}}+\frac{\partial^{2} w}{\partial z^{2}}\right] \text { (5) }
\end{aligned}
$$

Energy:

$\rho_{v} C_{p v}\left(u \frac{\partial T}{\partial x}+v \frac{\partial T}{\partial y}+w \frac{\partial T}{\partial z}\right)=\lambda_{v}\left(\frac{\partial^{2} T}{\partial x^{2}}+\frac{\partial^{2} T}{\partial y^{2}}+\frac{\partial^{2} T}{\partial z^{2}}\right)(6)$

Wick regions:

Mass:

$\frac{\partial u}{\partial x}+\frac{\partial v}{\partial y}+\frac{\partial w}{\partial z}=0$
Momentum:

$$
\begin{aligned}
& \frac{\rho_{l}}{\varepsilon}\left[u \frac{\partial u}{\partial x}+v \frac{\partial u}{\partial y}+w \frac{\partial u}{\partial z}\right]=-\frac{\partial p}{\partial x}-\frac{\mu_{l}}{K} u+ \\
& \frac{\mu_{1}}{\varepsilon}\left[\frac{\partial^{2} u}{\partial x^{2}}+\frac{\partial^{2} u}{\partial y^{2}}+\frac{\partial^{2} u}{\partial z^{2}}\right]-\frac{C_{E}}{K^{0.5}}|V| V \\
& \frac{\rho_{l}}{\varepsilon}\left[u \frac{\partial v}{\partial x}+v \frac{\partial v}{\partial y}+w \frac{\partial v}{\partial z}\right]=-\frac{\partial p}{\partial y}-\frac{\mu_{l}}{K} v+ \\
& \frac{\mu_{l}}{\varepsilon}\left[\frac{\partial^{2} v}{\partial x^{2}}+\frac{\partial^{2} v}{\partial y^{2}}+\frac{\partial^{2} v}{\partial z^{2}}\right]-\frac{C_{E}}{K^{0.5}}|V| V \\
& \frac{\rho_{l}}{\varepsilon}\left[u \frac{\partial w}{\partial x}+v \frac{\partial w}{\partial y}+w \frac{\partial w}{\partial z}\right]=-\frac{\partial p}{\partial z}-\frac{\mu_{l}}{K} w+ \\
& \frac{\mu_{l}}{\varepsilon}\left[\frac{\partial^{2} w}{\partial x^{2}}+\frac{\partial^{2} w}{\partial y^{2}}+\frac{\partial^{2} w}{\partial z^{2}}\right]-\frac{C_{E}}{K^{0.5}}|V| V
\end{aligned}
$$

Energy:

$$
\rho_{w} C_{p w}\left(u \frac{\partial T}{\partial x}+v \frac{\partial T}{\partial y}+w \frac{\partial T}{\partial z}\right)=\lambda_{w}\left(\frac{\partial^{2} T}{\partial x^{2}}+\frac{\partial^{2} T}{\partial y^{2}}+\frac{\partial^{2} T}{\partial z^{2}}\right)
$$

\section{Boundary conditions:}

Wicks / vapor interfaces:

The conservation of the mass at the wick / vapor interface applied, where:

$$
\dot{m}=-\rho_{v} w_{v}=\varepsilon \rho_{l} w_{l}
$$

To account for the thermal resistance at the $\mathrm{LV}$ interface, the evaporation and condensation mass fluxes are calculated from the kinetic theory of gases [7-8]:

$$
\dot{m}=a_{c c}\left(\frac{M}{2 \pi T_{i n}}\right)^{1 / 2}\left[p_{\text {sat }}\left(T_{\text {in }}\right)-p_{v}\right]
$$

And the energy balance at the liquid /vapor interface yields:

$$
\dot{m} C_{p l} T_{i n}-\lambda_{w} \frac{\partial T_{w}}{\partial n}=\dot{m} C_{p v} T_{i n}-\lambda_{v} \frac{\partial T_{v}}{\partial n}+\dot{m} h_{f g}
$$

To calculate pressure and velocities of the liquid and vapor, the local momentum equation at the interface is applied [2], which:

$$
p_{v}-p_{l}-\frac{\dot{m}}{2}\left(w_{v}-w_{l}\right)=2 \frac{\sigma}{r_{\text {eff }}}=p_{c}
$$

And, the continuity of shear stress at the interface gives [9]:

$$
\begin{aligned}
& \mu_{v} \frac{\partial u_{v}}{\partial z}=\mu_{l} \frac{\partial u_{l}}{\partial z}, \mu_{v} \frac{\partial v_{v}}{\partial z}=\mu_{l} \frac{\partial v_{l}}{\partial z} \\
& \text { Vapor region: } \\
& \text { At } x=0 \text { and } x=l \\
& \frac{\partial p}{\partial x}=0, u_{v}=0, v_{v}=0 \text {, and } w_{v}=0 \\
& \text { At } y=0 \text { and } y=W \\
& \frac{\partial p}{\partial y}=0, u_{v}=0, v_{v}=0 \text {, and } w_{v}=0
\end{aligned}
$$

Wick regions:

Liquid 1/copper solid wall interface:

$$
\frac{\partial p}{\partial z}=0, u_{l}=0, v_{l}=0 \text {, and } w_{l}=0
$$

Liquid 2/copper solid wall interface:

$\frac{\partial p}{\partial z}=0, u_{l}=0, v_{l}=0$, and $w_{l}=0$ 
The pressure gradient of liquid at liquid /vapor interface is assumed to follow the Darcy law:

$$
\frac{\partial p}{\partial z}=-\frac{\mu_{l} w_{l}}{K}
$$

To solve the energy equation, the following boundary conditions are applied:

Cooling fluid/ base plate interface:

$$
-\lambda_{b} \frac{\partial T}{\partial n}=h\left(T-T_{\infty}\right)
$$

Heater /heat input interface:

$$
-\lambda_{H} \frac{\partial T}{\partial n}=q "
$$
adiabatic:

All other surrounding walls surfaces are assumed

$$
\frac{\partial T}{\partial n}=0
$$

The governing equations were discretized using an implicit finite difference method [10-12], and the non linear term in the momentum and energy equations were discretized according to the linearization method by Wenk et al. [11] and Fletcher [13]. The computational code is written by Matlab program and the spatial grid size required for fast convergence was determined by trail and error [5].

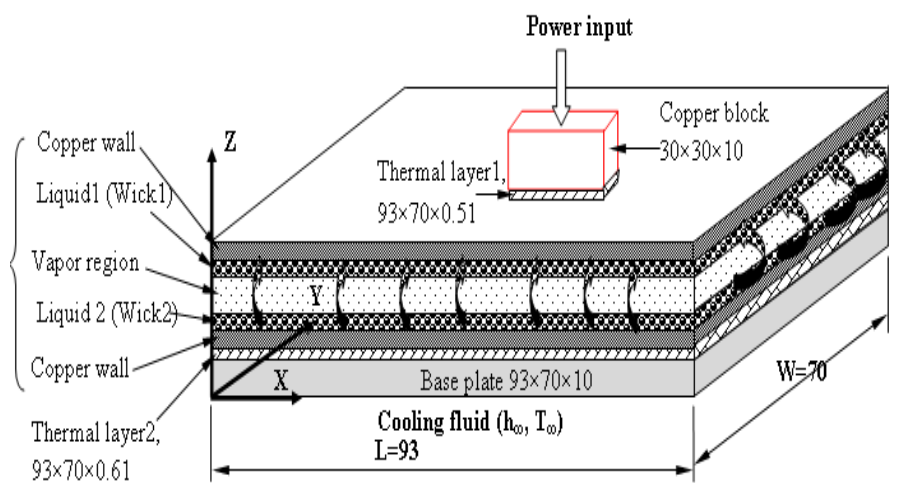

Figure 1: Details of the model and its dimensions in $\mathrm{mm}$

\section{Results and discussions}

The physical model used in our study as shown in figure1, consists of a copper heat pipe with the dimensions and characteristics shown in table 1 which is placed horizontal between the heat source (copper block) on the evaporator side (top surface) and a heat sink on the condenser side (bottom surface). All the material properties, wick characteristics and cooling fluid properties are shown in table2.

Table1: Heat pipe characteristics.

\begin{tabular}{|l|c|c|}
\hline Layer & Dimensions, mm & $\begin{array}{c}\text { Thermal } \\
\text { conductivity } \\
\text { W.m } \mathrm{m}^{-1} \cdot \mathrm{K}^{-1}\end{array}$ \\
\hline $\begin{array}{l}\text { Evaporator } \\
\text { (copper) }\end{array}$ & $93.6 \times 68.5 \times 1$ & 360 \\
\hline Condenser (copper) & $97.6 \times 72.5 \times 1$ & 360 \\
\hline wick & $93.6 \times 68.5 \times 1$ & 2.0 \\
\hline Vapor region & $93.6 \times 68.5 \times 1.3$ & \\
\hline
\end{tabular}

Table2: Material properties and cooling fluid parameters.

\begin{tabular}{|l|c|c|c|}
\hline Property & values & Property & Values \\
\hline $\begin{array}{l}\text { Wick } \\
\text { porosity }\end{array}$ & 0.5 & $\begin{array}{c}\text { Cooling fluid } \\
\text { heat transfer } \\
\text { coefficient }\end{array}$ & $\begin{array}{c}1450 \\
\mathrm{~W} \cdot \mathrm{m}^{-2} \cdot \mathrm{K}^{-1}\end{array}$ \\
\hline $\begin{array}{l}\text { Wick } \\
\text { permeability }\end{array}$ & $\begin{array}{c}0.52 \times 10^{-10} \\
\mathrm{~m}^{2}\end{array}$ & $\begin{array}{c}\text { Base plate } \\
\text { equivalent } \\
\text { thermal } \\
\text { conductivity }\end{array}$ & $\begin{array}{c}4 \\
\mathrm{~W} \cdot \mathrm{m}^{-1} \cdot \mathrm{K}^{-1}\end{array}$ \\
\hline $\begin{array}{l}\text { Heater block } \\
\text { thermal } \\
\text { conductivity }\end{array}$ & $\begin{array}{c}360 \\
\mathrm{~W} \cdot \mathrm{m}^{-1} \cdot \mathrm{K}^{-1}\end{array}$ & $\begin{array}{c}\text { Cooling fluid } \\
\text { temperature }\end{array}$ & $15^{\circ} \mathrm{C}$ \\
\hline
\end{tabular}

Figures 2 and 3 show the temperature distribution through the exterior surfaces of the heat pipe for power input $107 \mathrm{~W}$. Figure 2 shows the distribution at the top surface of the heat pipe (heat pipe/ thermal layer1 interface) and figure. 3 shows that distribution at the bottom surface of the heat pipe (heat pipe/thermal layer2 interface). The figures show that the symmetry of the temperature distribution with the symmetry of the model dimensions and heat flux input. Figure 2 shows that the maximum temperature difference at the top surface of the heat pipe is about $25{ }^{\circ} \mathrm{C}$. Figure 3 shows that the temperature at the condenser surface is about constant due the capability of the heat pipe to redistribution the heat flux flow from the surface of the heat source to a large plain surface (condenser side) by conduction and convection through the wick regions as will shown next to benefit for the heat convection cooling design.

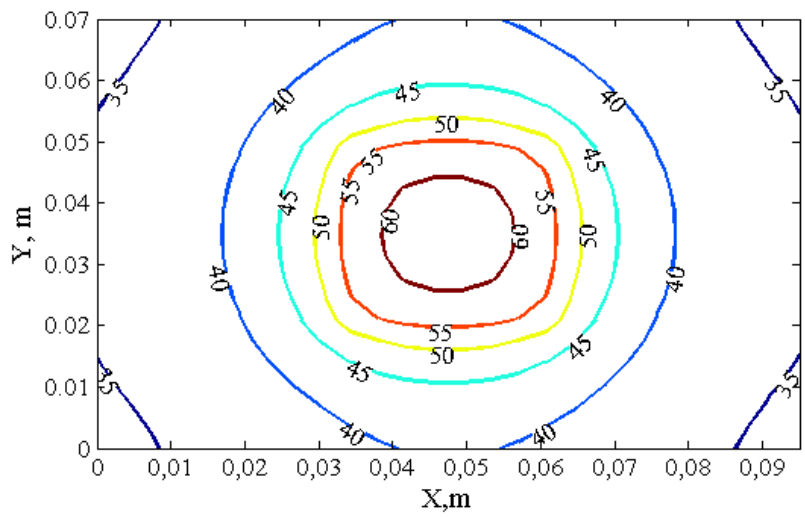

Figure 2. Temperature distribution at the top surface of the heat pipe $\left({ }^{\circ} \mathrm{C}\right)$.

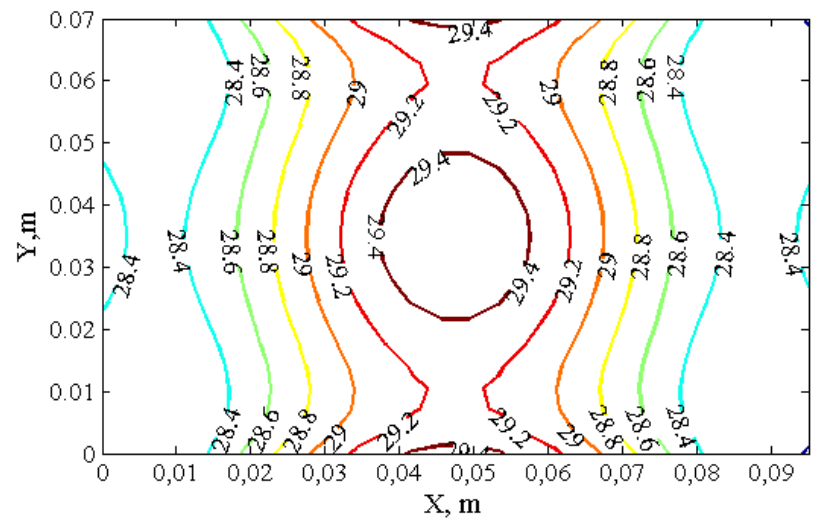

Figure3. Temperature distribution at the bottom surface of the heat pipe $\left({ }^{\circ} \mathrm{C}\right)$. 


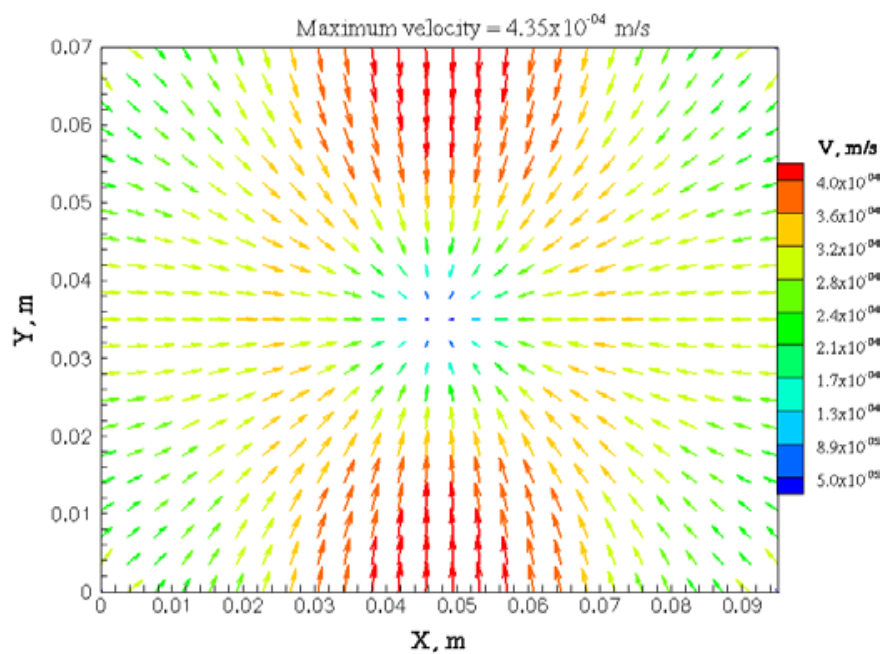

Figure 4 . Velocity vector distribution for $x y$ at the mid plane of liquid 1 .

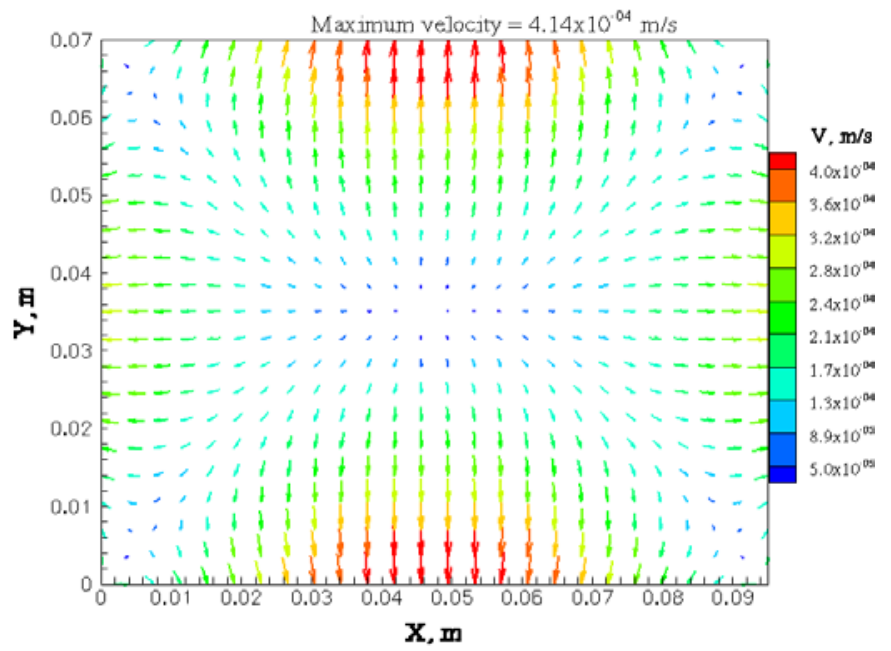

Figure 5. Velocity vector distribution for xy at the mid plane of liquid 2.

The heat transfer during the wick regions is transmitted by the conduction and the convection in the working fluid. Also the conservation of the mass in these regions is accomplished by the return of the liquid from the wick region 2 to the wick region 1 by the capillarity action. The velocity vector distribution through the $x y$ plane for liquid 1 and liquid 2 for power input $107 \mathrm{~W}$ are shown in figures 4 and 5 respectively. The results are shown at the mid plane of the liquid regions through $\mathrm{z}$ direction. The results show that through the wick 1 region, the liquid enters this region through the side wall to compensate the mass evaporated through the evaporation. Contrarily, for wick region 2, we found that the liquid exits from the wick region through the side walls due to the mass condensed inside the wick 2 region to conserve the liquid mass at these regions. That distribution of the velocity through the wick region 2 helps to reach a uniform temperature distribution through the condenser surface. Thus, due to transmitting the heat from the center of the wick region 2 to the outer surfaces by the convection force as indicated in figure 3 . From figures 4 and 5, we find that the velocity of the wick diminishes as approaching to the wick corners due to decreasing the heat transfer at these positions. Also these velocity approaches to zero as approaching to the centre due to increasing the mass evaporated or condensed. They also show that the maximum velocity for liquid 1 is about $4.35 \times 10^{-4} \mathrm{~m} / \mathrm{s}$ and for liquid 2 is about $4.14 \times 10^{-4} \mathrm{~m} / \mathrm{s}$.

These results will be clearer when we analyze the velocity vector distribution at liquid regions through $\mathrm{z}$ direction as shown in figures 6 and 7. Figure 6 shows the velocity vector and streamlines distribution for liquid 1 through $\mathrm{xz}$ plane and y equals to $\mathrm{w} / 2$ and the same results for the same position for liquid 2 are shown in figure 7 . The velocity vector and streamlines distributions at figure 6 show that the flow of liquid enters the wick region 1 through the side walls and exits through wick1/vapor interface to evaporate through that interface. Figure 7 shows that the mass condensed inside wick 2 at the wick2/vapor interface exits through the side walls to return to wick 1 to compensate the mass evaporated. These results agree with the physical phenomena of the circulation of the liquid throughout the wick region for that construction of heat pipe. They also show that the velocity increases with approaching to the liquid/vapor interface through $\mathrm{z}$ direction. By analyzing the velocity distribution in $\mathrm{z}$ direction, we found that, as approaching to $\mathrm{x}=0.045 \mathrm{~m}$, the velocity is vertical which implies that the convection heat transfer at this direction is mainly in $\mathrm{z}$ direction.

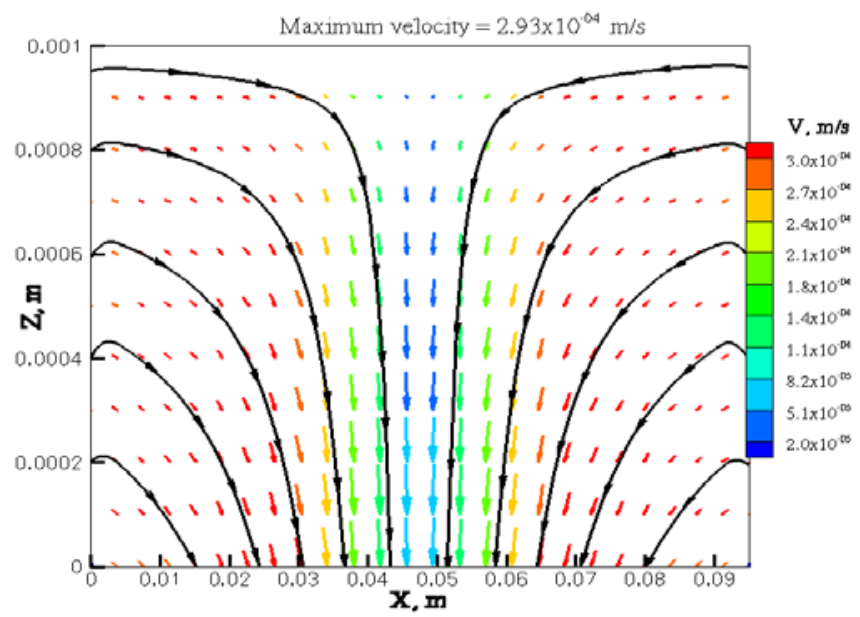

Figure 6. Velocity vector and streamlines distribution through the thickness of liquid1 for $x z$ plane at $y=W / 2$. 


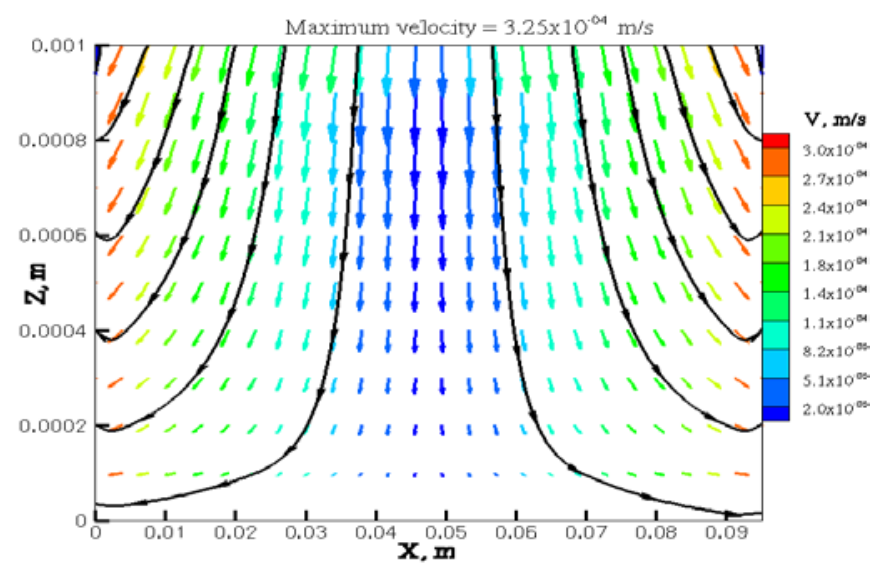

Figure 7. Velocity vector and streamlines distribution through the thickness of liquid2 for xz plane at $y=W / 2$.

As the mass evaporated at wick1/ vapor interface (evaporator side), the vapor flows through the vapor region carrying the heat energy due to evaporation until it condenses at the wick2/vapor interface (condenser side) releasing this heat energy. The hydrodynamic model is used also to calculate the velocity distribution through the vapor region as shown in figures 8 and 9. Figure 8 shows the velocity vector distribution through the thickness of vapor region for $\mathrm{xz}$ plane and $\mathrm{y}=\mathrm{w} / 2$ for power input of $107 \mathrm{~W}$. The velocity vector distribution for $\mathrm{xz}$ place at mid plane through $\mathrm{z}$ direction of the vapor region for the same power input is shown in figure 9. Figure 8 shows that the evaporation velocity inters the vapor region at liquid1/ vapor interface and exits from the vapor regions at liquid2/vapor interface and the uniformity of the velocity distribution increases with decrease $\mathrm{z}$ direction which accords with the physics of the evaporation condensation phenomena. Figures 8 and 9 show that the maximum velocity at $\mathrm{xz}$ plane is about $0.22 \mathrm{~m} / \mathrm{s}$ and at $\mathrm{xy}$ plane is about $0.028 \mathrm{~m} / \mathrm{s}$. The results show that vertical component of the vapor velocity is greater than the horizontal component, and this means, the main heat transfer in the vapor region in the vertical direction ( $\mathrm{z}$ direction). By comparing the values of the velocity of the liquid and vapor velocity we find that, the vapor velocity is about $10^{3}$ of the liquid velocity and so earlier studies neglected the liquid velocity effect in their model. But this effect must be taken because the mass of the liquid is about $10^{3}$ of the mass of the vapor.

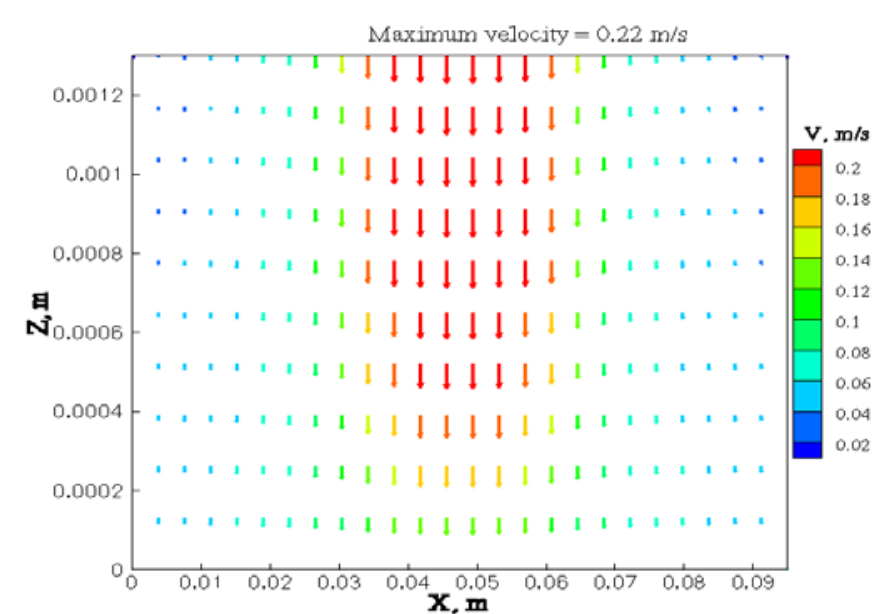

Figure 8. Velocity vector distribution through the thickness of the vapor region for $x z$ plane and at $y=W / 2$.

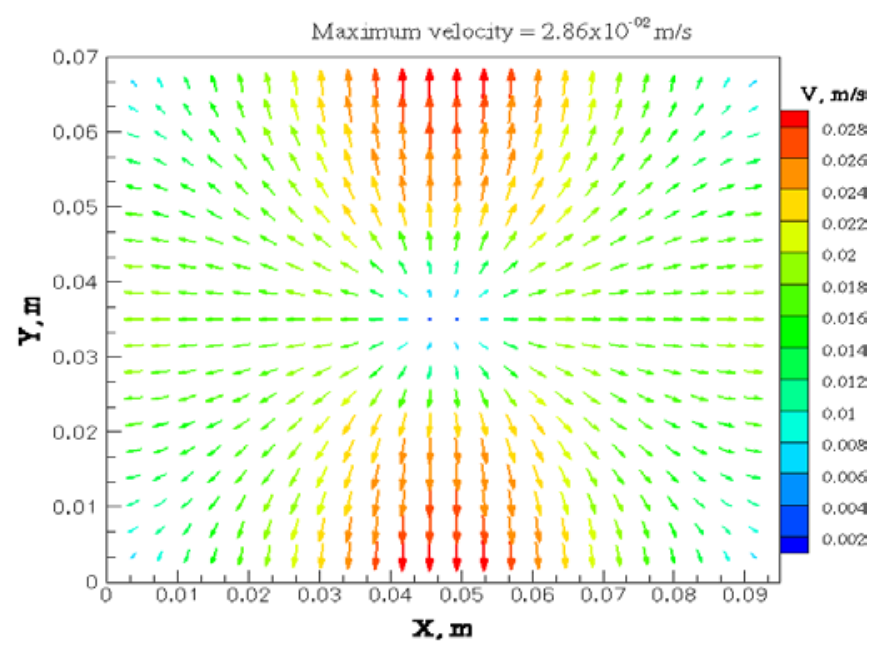

Figure 9. Velocity vector distribution of vapor region for xy plane at mid plane of vertical direction.

\section{Conclusion}

A three dimensional model coupling the hydrodynamic and thermal models was presented for the cooling of an electronic component by a flat heat pipe. In the hydrodynamic model, a connecting between wick regions 1 and 2 is achieved during a return wick having the thickness of the wick region. The results show that the hydrodynamic model illustrates well the flow of the liquid through the wick and vapor regions and it also illustrates the return of the liquid from wick 2 to wick 1 trough the returning layer to conserve the mass during these regions. The results also show that for power input $107 \mathrm{~W}$, the maximum vapor velocity is about $0.22 \mathrm{~m} / \mathrm{s}$ and the liquid velocity is about $4.35 \times 10^{-4} \mathrm{~m} / \mathrm{s}$. By using this 3D numerical model, the effect of heat pipe parameters (wick and vapor properties, etc..) on the cooling process will be studied. 


\section{References}

[1] Tan, B. K., Huang, X. Y., Wong, T. N., Ooi, K.T., 2000. A study of multiple heat sources on a flat plate heat pipe using a point source approach, international journal of heat and mass transfer 43, 3755-3764.

[2] Wang, Y., Vafai, K., 2000. An experimental investigation of the thermal performance of an asymmetrical flat plate heat pipe, International Journal of Heat and Mass Transfer 43, 2657-2668.

[3] Carbajal, G., Sobhan, C. B., Peterson, G.P., Queheillalt, D.,T., Wadley, H.N.G., 2006. Thermal response of a flat heat pipe sandwich structure to a localized heat flux, International Journal of Heat and Mass Transfer 49, 4070-4081.

[4] Xiao, B., Faghri, A., 2008. A three dimensional thermal fluid analysis of flat heat pipes, International journal of heat and mass transfer 51, 3113-3126.

[5] Sonan, R., Harmand, S., Pellé, J., Leger, D., Fakès, M., 2008. Transient thermal and hydrodynamic model of flat heat pipe for the cooling of electronic components, International journal of heat and mass transfer, 51, 6006-6017.

[6] Ranjan, R., Murthy, J.Y., Garimella, S.V., Vadakkan, U., 2011, A numerical model for transport in flat heat pipes considering wick microstructure effects, international journal of heat and mass transfer, 54,153-168.

[7] Towwier, J.M., Elgenr, M. S., 1994. A heat pipe transient analysis model, int. journal heat and mass transfer, 37. 5, 753-762.

[8] Eames, I. W., Marr, N. J., and Sabir, H., 1997. The evaporation coefficient of water: a review, int. journal heat and mass transfer, 40, 29632973.

[9] Tsay, Y.L., Lin, T.F., Yan, W.M., 1990. Cooling of falling liquid film through interfacial heat and mass transfer, internat. J. Multiple flow 16, 853-273

[10] Wenk, W.D., Ramshaw, J. D., Trapp, J. A., Hughes, E. D., and Solbrig, C.W., 1975, Transient three dimensional thermal hydraulic analysis of nuclear reactor fuel rod analysis: General equations and numerical scheme, Aerojet Nuclear company, ANCR-1207.

[11] Patenker, S.V., 1980. Numerical heat transfer and fluid flow, Mc Graw-Hill, New York.

[12] Takemitso, N., 1986. An imlicit finite difference method to solve incompressible fluid flow, Bulletin JSME, 29 , 33193327.

[13] Fletcher, C. A. J., 1991. Computational for fluid dynamics, second edition, Springer-Verlag, Sydney, 330-374. 